\title{
César Vallejo. Sentimiento y otredad en su poesía ${ }^{30}$ César Vallejo. Feeling and otherness in his poetry
}

\author{
Darío Henao Restrepo
}

Recibido: 20 de Agosto 2011. Aprobado: 15 de Septiembre 2011

\begin{abstract}
Resumen
La obra de César Vallejo es de significación universal, en ella Historia y drama íntimo se conjugan en este sentir profundo que constituye la modulación esencial de la vida para el poeta peruano, de ahí el impacto que causó en los años 60 y 70 en las jóvenes comunidades ansiosas cambiar el mundo. El autor sostiene que la dimensión ética de la conciencia de Vallejo para poetizar emociones auscultadas en sus herencias, conflictos, frustraciones y esperanzas es la conexión profunda que alcanza el poeta con el medio colectivo. El sentimiento y la otredad en la poesía de Vallejo se configuran en la percepción de los desgarramientos de la época y logra con su percepción de la muerte anterior a la vida configurar una hermenéutica vallejiana que le conservan vigente por su misterio y le ubican entre los más grandes poetas del siglo XX.
\end{abstract}

Palabras clave: César Vallejo; Poesía peruana; Poesía latinoamericana.

\begin{abstract}
César Vallejo's work is of universal significance in her history and intimate drama combine in this deep feeling which constitutes the essential modulation of life for the Peruvian poet, hence the impact it had on the 60 and 70 in young communities eager to change the world. The author argues that the ethical dimension of consciousness Vallejo poetize auscultated emotions on their inheritances, conflicts, frustrations and hopes is the deep connection that reaches the poet with the collective means. The feeling and otherness in the poetry of Vallejo are configured in the perception of tears in the time and manages your perception of death before life set an vallejiana hermeneutics to retain its mystery and force him rank among the most great poets of the twentieth century.
\end{abstract}

Keywords: César Vallejo; Peruvian poetry; Latin American poetry.

";Ah mi amigo Vicente Huidobro, no he de transigir nunca con Usted en la excesiva importancia que Usted da a la inteligencia en la vida. Mis votos son siempre por la sensibilidad."

César Vallejo

1.

\footnotetext{
${ }^{30}$ Ensayo de sistematización presentado en el Congreso internacional "César Vallejo, telúrico y magnético (18922012)" organizado por la Academia Peruana de la Lengua y la Facultad de Letras y Ciencias Humanas de la Universidad de San Marcos. 7,8 y 9 de noviembre de 2012.
} 
Volver a César Vallejo, a tantos años de las primeras lecturas, quizás las más emotivas y fragmentadas, recuerdan las lecturas e ideas que forjaron mi sensibilidad y visión del mundo en la educación secundaria a finales de los años 60 y la universitaria en los años 70. Tiempos de revoluciones y utopías para los jóvenes latinoamericanos de entonces. Todos leíamos al gran César Vallejo con la misma devoción con la cual leíamos a Carlos Marx. Ese código, el del marxismo, entre los muchos que entretejen su extraordinaria obra, fue preponderante, y arriesgo explicarlo hoy, por la identificación fuerte y profunda con ese dolor de humanidad que nos provocaba su poesía.

Los Heraldos Negros, Trilce, Poemas Humanos y España aparta de mí este cáliz tocaban nuestras fibras más íntimas mientras soñábamos con cambiar el mundo. Poemas como La cena miserable apuntalaban nuestra utopía:

Y cuándo nos veremos con los demás, al borde

De una mañana eterna, desayunados todos.

Hasta cuándo este valle de lágrimas, a donde

Yo nunca dije que me trajeran.

El ideal "Desayunados todos" inspiraba nuestros sentimientos de solidaridad y las acciones con las que creíamos podíamos contribuir a que las mayorías humildes tuvieran un lugar digno en este mundo. El profundo humanismo presente en la obra de Vallejo, con ese sui generis tempero de cristianismo y marxismo, fue fundamental para la formación de la sensibilidad de muchos de los jóvenes de entonces. Los versos de Masa, sobrecogedores por su esperanzadora utopía, alimentaban el credo y la devoción religiosa por una causa.

2.

Leyendo a Vallejo nos acercamos al Perú profundo y a su historia, materia que se completaba, por supuesto, con las obras de José Carlos Mariátegui y José María Arguedas. Fueron lecturas definitivas, imposibles de olvidar, savia vital de una visión del mundo que nos hace latinoamericanos. Por estas razones, Vallejo sigue en mi memoria, reconociendo, eso sí, el recorrido de otras lecturas a través de los años atisbando otros códigos y dimensiones en ese primer Vallejo. Como dice el poeta Marco Martos, gestor e

Poligramas 36, segundo semestre 2011, ISSN 0120-4130. 
inspirador de este Congreso, sólo haciendo comparecer todos los códigos es posible una lectura a plenitud de Vallejo. Está, primero, según él, el código peruano popular y culto. Pero están también los códigos literarios hispano-americanos, españoles, franceses, rusos, norteamericanos y alemanes. El código marxista. El católico. El nietzcheano. El soviético revolucionario. El parisino. El de la guerra civil española. El tecnológico. El medio masivo. El del cuerpo humano. El del amor. El de la familia. En fin, tantas como inagotables facetas de una obra de significación universal.

La profunda emoción y la materia transpuesta en su poesía se metaforizan en los versos como los que cierran su espléndido poema, Telúrica y magnética:

Lo entiendo todo en dos flautas

$\mathrm{Y}$ me doy a entender en una quena!

¡Y lo demás, me las pelan...!

"Me doy a entender en una quena" sintetiza tanto su mundo personal como todo el mundo andino y su historia. Historia y drama íntimo se conjugan en este sentir profundo que constituye la modulación esencial de la vida para César Vallejo. Según leemos en su polémica del indigenismo en materia de arte americano, él le concede primacía a la sensibilidad indígena sobre la voluntad indigenista. Su conexión es profunda con el medio colectivo donde instala la dimensión ética de su conciencia para poetizar emociones auscultadas en sus herencias, conflictos, frustraciones y esperanzas: aquella inefable melancolía del alma india, en la que ejerce el poeta su otredad, con la rica gama de entonaciones de la lengua castellana, con ritmos y matices de una multiplicidad inagotable en su poesía. Tal como se pulsa en los versos de su poema Aldeana:

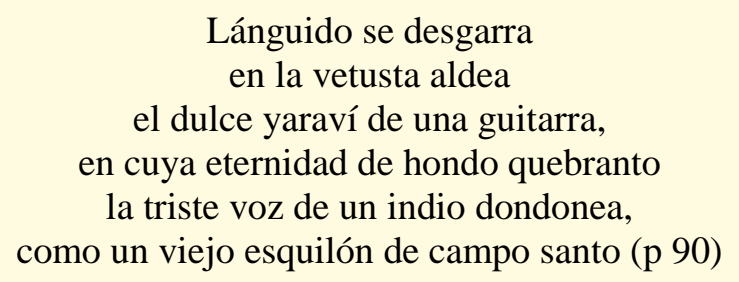

"El dulce yaraví de una guitarra" hace parte de ese aire de familia de los países andinos y de la trágica llegada del Imperio Español y la constitución de su poderío sobre el despojo y la gran mortandad de esplendidas civilizaciones. 
Esta sensibilidad en algo remite a Porfirio Barba Jacob, el bardo maldito de las letras colombianas, o un tanto a la depurada melancolía de Aurelio Arturo en Morada al sur. De Porfirio menciono uno de los poemas más recitados por los colombianos - Canción de la vida profunda - y en el que podemos delinear nuestro lugar.

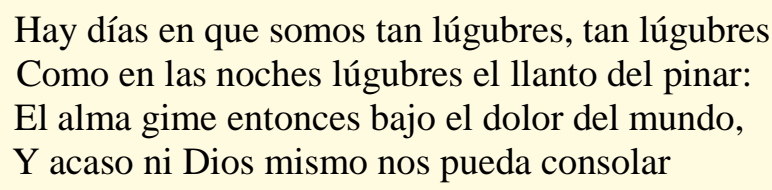

De Aurelio, tal vez es cierta nostalgia y melancolía la que nos sugiere proximidades con Vallejo.

Te hablo de un bosque extasiado que existe

Sólo para el oído,

Y que en el fondo de las noches pulsa

Violas, arpas, laúdes, y lluvias sempiternas

"El alma gime entonces bajo el dolor del mundo" y "Violas, arpas, laúdes, y lluvias sempiternas" de Barba y Arturo, entre las tantas y misteriosas asociaciones posibles, se emparentan con la "eternidad de hondo quebranto" de Vallejo y aquí sirven para evidenciar el lugar desde donde vuelvo para pensar un poco sobre el sentimiento y la otredad en su poesía. Son los motivos más recónditos, las heridas del corazón, como especie de biografía irracional, con los cuales Vallejo va a construir su deslumbrante obra, ese yo poético dialogante dirigido a un TÚ múltiple.

El mundo andino de Vallejo, como diría Guimaraes Rosa de su sertón, está en todas partes en su poesía, con sus ambigüedades, "Todo es y no es", sea que esté en Rusia, Francia, España o el Perú. Es ese mundo y la sensibilidad contenida en él desde el cual siempre se expresa la posición del poeta. Posición sumamente hermética que se revela en el lenguaje y a través de él. Lo popular y lo culto se conjugan con el proceso histórico y todas sus mitologías, con una concepción metafísica alimentada por su tránsito del catolicismo al marxismo. El sentimiento y la otredad en la poesía de Vallejo se configura en la percepción de los desgarramientos de la época - las primeras décadas de esa era de extremos como llama Erich Hosbwan al siglo XX - a la par con otros poetas de otras tradiciones culturales que las sufrieron. En el caso de Vallejo, al igual que muchos latinoamericanos, su obra da cuenta de todas las paradojas del mundo moderno, de todas las tensiones y disparidades entre sus ideas de avanzada y el ambiente tradicional de la 
provincia y las estructuras de atraso y desigualdad en el Perú. Todo esto que podríamos llamar marchas y contramarchas de la modernidad, con todas las peculiaridades en el continente y en sus diversas regiones, son la materia vertiente que su poesía traduce en ritmos, en indecisiones, en decursos y fluideces, en una dimensión íntima. Como diría Fernando Pessoa en lo que consideraba los dos principios generales de todo estilo: decir lo que se siente exactamente cómo se siente - claramente si es claro; oscuramente, si es oscuro; confusamente, si es confuso. (p.45) Todo sobre una gramática muy singular en el caso de Vallejo, en particular en Trilce, donde se aprecia la lucha entre el alma del poeta y el idioma, conflicto que para José María Arguedas deviene del brutal encuentro de lo andino con lo hispánico, del quechua con el castellano.

Vallejo poetizó todas las complejas realidades que vivió en su tiempo, las personales y colectivas, con sentimientos de ternura y solidaridad, pero también de dolor, de pesimismo, de reclamo y de estremecimiento, asumiendo el pasar de la vida, "como raro espejismo", "ir muriendo y cantando", "en mi aire metafísico que nadie ha de palpar" y tantos versos que expresan su mundo de silencios y obstinadas interrogaciones, de sus protestas, de secretos empozados "como charco de culpa". Como él mismo define sus sentimientos y su condición: “¡Ay, cómo la sensación arruga tanto!” "mas mi triste tristumbre se compone de cólera y tristeza" (232), estas definiciones de su Yo profundo son constantes. Vallejo capta el decurso interior de su vida como una gran cantidad de seres que fue y sigue siendo, ese otro que fue y ahora es ajeno, en fin ese somos muchos que en su poesía dialoga consigo mismo y con el otro. Este es el gran misterio de su poética, que el mismo sintetizó: ("Y no saben que el misterio sintetiza") en los primeros versos de Intensidad y altura de sus poemas póstumos.

Quiero escribir, pero me sale espuma quiero decir muchísimo y me atollo; no hay cifra hablada que no sea suma, no hay pirámide escrita sin cogollo. (236)

Vallejo nos trasmite en su poesía, más que angustia y desesperación, sentimientos de profunda ternura, solidaridad y amistad; otras veces, lúcida y estremecida resignación, cuando no la permanente alusión al ciclo vida/muerte, a su "muerte propia" tantas veces referida en todos sus libros. El poema Piedra negra sobre una piedra blanca de su libro Poemas Humanos contiene su concepción de la vida como muerte anticipada: 
Me moriré en París con aguacero,

un día del cual tengo ya el recuerdo.

Me moriré en París - y no me corro -

Tal vez un jueves, como es hoy, de otoño

Jueves será, porque hoy, jueves, que proso

estos versos, los húmeros me he puesto

a la mala y, jamás como hoy, me he vuelto,

con todo mi camino, a verme solo.

César Vallejo ha muerto, le pegaban

todos sin que él les haga nada;

le daban duro con un palo y duro

también con una soga; son testigos

los días jueves y los huesos húmeros,

la soledad, la lluvia, los caminos ... (233)

La muerte para Vallejo es anterior a la vida, una especie de otredad anticipada, con lo cual rompe el circulo de la identidad vida y muerte a la manera de Quevedo - "la cuna y la sepultura"- o el "ser-para-la muerte" de Heidegger; aquí trastoca la consecuencia lógica vivir y morir para introducir el misterioso absurdo de la "sepultura" como algo anterior a la "cuna". Esto nos lleva a una de las vetas filosóficas más rica y compleja de la hermenéutica vallejiana.

"La soledad, la lluvia, los caminos..." dejan en abierto la singular postura de Vallejo y me dan pie para leer el poema Soledad de César Vallejo

Las personas mayores ya se han ido y jamás volverán, viven en nunca, han viajado a los fondos de la muerte y nos hemos quedado con el ciego Santiago tanteando en los más duro del nocturno metal de negro fuego. Nadie nos habla, estamos en el fuego, Son nuestros el silencio que se ha ido Convirtiendo en el hábito más duro, Idiomas de la niebla con su nunca, Los ojos de los sueños y del ciego Observar de la vida halando muerte. Sabemos que la vida trae muerte, Escondido meollo de oro y fuego Que llega al más vidente y frágil ciego, A todos los más grandes que se han ido Por la ruta de Orfeo, hasta el que nunca Soñó con la blandura de lo duro.

Comentan que la vida es algo duro, ¿saben de la blandura de la muerte?

Poligramas 36, segundo semestre 2011, ISSN 0120-4130. 
¿con quién mamá estará en el jamás nunca?

¿a quién aplacará con nieve o juego?

Sabemos que no está, que bien se ha ido,

Que hemos sido guardados por el ciego.

Nadie nos acompaña, sino ciego,

Nadie comenta nada y lo más duro

Es saber que la vida ya se ha ido

A su fin natural: la misma muerte.

Las sonrisas marcadas con el fuego

De lo inerte ya viven en el nunca.

Nacemos y morimos solos, nunca

Traemos diferente el sino ciego,

Así es toda la vida con su fuego;

Mayores delanteros en lo duro

De acercarse muy rápido a la muerte,

Apenas han nacido, ya se han ido.

Lo oído, lo perdido en lo que nunca

Volverá de la muerte, salvo en ciego

Sueño, se torna llama, duro fuego.

Mar de las tinieblas, 1999, p.413

3.

Junto a Saramago, Pessoa, Kavafis, Witman, Borges, Lezama Lima, entre tantos, la dimensión de Vallejo se crece y su voz se erige y se confirma como uno de los grandes poetas del siglo $\mathrm{XX}$. 